\title{
SÉANCE DU 10 OCTOBRE 1913
}

Présidence DE M. DANGEARD, VICE-PRÉSIDENT.

M. le Secrétaire général donne lecture du procès-verbal de la dernière séance, dont la rédaction est adoptée.

Il donne ensuite lecture d'une lettre de M. Chauveaud, président, qui s'excuse de ne pouvoir assister à la séance.

M. le Président a le regret de faire part à la Société du décès de M. Malinvaud, ancien secrétaire général et ancien président. Il retrace la carrière scientifique du défunt et rappelle les services éminents qu'il a rendus à la Société au cours de ses années de secrétariat général, puis comme président, archiviste et membre du Conseil. Il se fait l'interprète des sentiments attristés de la Société, ì laquelle nulle perte ne pouvait être plus sensible. Une notice biographique sera publiée ultérieurement sur notre collègue.

Deux autres décès se sont encore produits pendant les vacances, ceux de MM. Réchin et Jean Bonnet.

L'abbé Jules Réchin, qui appartenait à notre Société depuis plus de trente ans, s'était spécialisé dans l'étude des Mousses. Très bien doué physiquement, il consacrait chaque année une partie de ses vacances à l'exploration de quelque chaine de montagnes et, ces dernières années, à celles de la Savoie. Ceux d'entre nous qui ont fréquentẻ les Sessions extraordinaires se rappellent la bonne humeur et l'entrain de ce gai compagnon; tous ceux qui ont été en relations scientifiques avec lui ont eu is se louer de sa parfaite complaisance et regretteront que sa modestie et aussi des occupations professionnelles absorbantes ne lui aient pas permis de publier plus souvent le résultat de ses observations. Il est mort subitement, le 14 aoùt dernier, à Pralognan (Savoie).

M. Jean Bonnet, un de nos plus jeunes confrères, s'était déji fait connaitre par plusieurs travaux intéressants. Le malheureux jeune homme, qui faisait son service militaire aux chasseurs alpins, a trouvé une mort affreuse dans la catastrophe de Villeneuve-Loubet.

M. le Président annonce ensuite une nouvelle présentation. T. LX. (SÉANCES) 31 


\section{$2 \mathrm{BHL}$ Biodiversity Heritage Library}

1913. "Séance Du 10 Octobre 1913." Bulletin de la Société botanique de France 60, 473-473. https://doi.org/10.1080/00378941.1913.10836656.

View This Item Online: https://www.biodiversitylibrary.org/item/8682

DOI: https://doi.org/10.1080/00378941.1913.10836656

Permalink: https://www.biodiversitylibrary.org/partpdf/160956

\section{Holding Institution}

Missouri Botanical Garden, Peter H. Raven Library

\section{Sponsored by}

Missouri Botanical Garden

\section{Copyright \& Reuse}

Copyright Status: Public domain. The BHL considers that this work is no longer under copyright protection.

This document was created from content at the Biodiversity Heritage Library, the world's largest open access digital library for biodiversity literature and archives. Visit BHL at https://www.biodiversitylibrary.org. 